\title{
La herencia lingüística canaria en la frontera mexicana con Belice
}

\author{
The Canarian linguistic heritage \\ in the Mexican border with Belize
}

\author{
Raúl Arístides Pérez Aguilar \\ Universidad de Quintana Roo \\ rauperez@uqroo.edu.mx
}

RESUMEN: Se estudia una serie de palabras que llegaron a la frontera mexicana con Belice durante la primera mitad del siglo XVIII junto con los colonos canarios traídos por el gobernador de Yucatán para repoblar la villa de Salamanca de Bacalar, construir un fuerte y así detener el avance en territorio mexicano de los ingleses aposentados en la región. Se trata de verbos, sustantivos y adjetivos que se incrustaron en ciertos bloques de la vida material de la sociedad bacalareña conformada por indios, mestizos y españoles cuyos porcentajes semejantes permitieron el arraigo y la difusión de estas voces que aún gozan de singular vitalidad en ambos lados del río Hondo.

Palabras clave: Léxico, Belice, Frontera, Canarismos, Yucatán.

ABSTRACT: A series of words that arrived in the Mexican border with Belize during the first half of the XVIII century with Canarian colonizers whom were brought by the governor of Yucatán to populate the village of Salamanca de Bacalar in order to built a fortress to stop the English advance in the region. It is about verbs, nouns and adjectives that became embedded within certain blocks of the material life of the society from Bacalar made of indios, mestizos and Spanish whom their percentages allowed the ingrainment and diffusion of these voices which until today still have a peculiar vitality on both sides of the river.

Keywords: Lexicon, Belize, Border, Canarisms, Yucatán. 


\section{INTRODUCCIÓN}

En una carta del juez de registro de Santa Cruz de Tenerife con fecha 21 de julio de 1734, se asienta el embarque hacia la villa de Uacalar en Yucatán de 64 personas (Morales Padrón, 1950: 7) que son las mismas que aparecen registradas como 12 familias más 2 personas en el navío Santísima Trinidad Nuestra Señora del Rosario y San José que zarpó de ese mismo puerto ese mes, y que ya había hecho una travesía anterior —en 1727- para dejar en Puerto Rico a 30 familias isleñas que debieron ser 32 según los documentos de registro del barco (García Bernal, 2000: 1987).

En 1733, el navío San Salvador, que zarpó de La Palma el 19 de noviembre, había depositado en San Francisco de Campeche a 36 personas cuyo destino era la misma villa (Morales Padrón, 1950: 20). El 17 de abril de 1735, zarpó de Tenerife Nuestra Señora de la Candelaria, San José y las Ánimas, mejor conocido como "El Palmero", con nueve familias más 4 personas con el mismo derrotero (García Bernal, 2000: 1986).

Éstos son los tres únicos viajes registrados de Canarias a San Francisco de Campeche con pasajeros destinados a habitar en Bacalar entre 1700 y 1750. Sin embargo, ya desde 1727, el gobernador de Yucatán Antonio Figueroa y Silva había recibido instrucciones de la corona española para repoblar la antigua villa con colonos del archipiélago de las Canarias ${ }^{1}$ y construir una guarnición en esa plaza con objeto de realizar operaciones sobre Belice e impedir la progresión de los ingleses al norte del río Hondo. Es así como ese mismo año, la abandonada villa desde fines del siglo XVII pretendió ser reconstruida, fortificada y repoblada. El gobernador se puso al frente de los soldados y marchó a Bacalar (Conover, 2013: 54); allá, repartió tierras y solares, se inició la labranza así como la edificación del fuerte, en 1729, con la advocación de San Felipe ${ }^{2}$, construcción culminada en su primera etapa en 1732.

No hay datos de los canarios a quienes el gobernador benefició con tierras y trabajo en esa primera fase de repoblación del área en 1733. El número de colonos de los tres arribos ya comentados llega a "149 a la Villa de Vacalar" (Pérez Vidal, 1955: 121) ${ }^{3}$, distribuidos en 28 familias más 9 personas ${ }^{4}$.

\footnotetext{
${ }^{1}$ Conover (2013: 54) señala en una nota que "se desconoce si los pobladores de Bacalar fueron migrantes canarios, como era la intención de Figueroa", y que años después (1759), el gobernador de Yucatán, Alonso Fernández, solicitó 100 familias canarias para colonizar aquel paraje de la península yucateca sin que se asegure que hayan sido enviadas.

${ }^{2}$ Se cuenta, dice Conover (2013: 54), que el gobernador encontró los restos de la población que había sido abandonada alrededor de medio siglo atrás, así como los de las iglesias de Nuestra Señora del Triunfo y de San Juan construidas en el siglo XVII, los de la casa real, de la prisión y de algunas casas españolas.

${ }^{3}$ Ya en el año de 1682 se documenta la salida de "77 soldados con rumbo a Yucatán y San
} 
No fueron estos canarios los primeros que involucraron su habla con la de los naturales en el período de repoblación ${ }^{5}$ que incluyó las actividades agrícolas de unos y las de la construcción de otros, pues es de esperarse que estos colonos conocieran los procesos del cultivo de la caña de azúcar y fueran algunos —quizás_ "maestros de ingenio" o "maestros de azúcar" así como poseedores de una herencia sabida de antepasados portugueses quienes llegaron a alcanzar la tercera o la cuarta parte de la población de La Palma y Tenerife, lugares de donde provenía la mayoría de ellos.

No es difícil conjeturar el grado de convivencia que debió existir entre los colonos y entre éstos y la población originaria seguramente mayoritaria ${ }^{6}$. La ayuda mutua que se prestaron ambos grupos en cuestiones agrícolas ${ }^{7}$, en herbolaria y otros asuntos ${ }^{8}$ hizo que intercambiaran formas linguiísticas nuevas y viejas que compartieron entre todos primero, y que fueron esparciendo más allá de los límites del poblado que alcanzaba los 600 metros de norte a sur y 320 de este a oeste (Antovich y Alonzo, 2010: 39) al entablar relaciones de comercio y de amistad con las rancherías cercanas y con el pueblo de Chunhuhub situado 40 leguas al norte.

La presencia abundante de los canarios en esas tierras fue sin duda novedosa para la población cuyos abuelos o bisabuelos habían huido de Bacalar

Francisco de Campeche" sin que se sepa si en verdad arribaron, y de otra más compuesta por 28 familias destinadas a Campeche el año anterior (Pérez Vidal, 1955: 116).

${ }^{4}$ La corona española fomentó la migración de familias canarias al Circuncaribe desde mediados del siglo XVII debido a la buena fama de los isleños como hábiles agricultores, constructores y marineros. Así llegaron muchos a Cuba, Santo Domingo, Puerto Rico, Venezuela, Texas, Florida y a las tierras limítrofes de la Nueva España.

${ }^{5}$ Las autoridades de Bacalar eran mestizas o castellanas así como algunos elementos del ejército que custodiaba la zona en conflicto con los ingleses en el que también había gallegos, aragoneses y andaluces según Conover (2013: 56).

${ }^{6}$ Es necesario aclarar que la población no indígena de Bacalar fue reducida pues no pasaba de 123 individuos en 1688, y que la mayoría era indígena que hacia 1640 rebasaba las 240 personas. Por otro lado, las referencias sobre la población de Bacalar es múltiple y variada. Gerhard (1991: 51) dice que había 1000 indígenas en 1736 en el partido de Bacalar que incluía no sólo a esta villa, sino a varios pueblos. Lucas de Gálvez, en 1789, calcula 1400 indígenas que vivían en el pueblo de Chichanhá y la villa de Bacalar (Conover, 2013: 20). Calderón (1953: 215) dice que la población de la villa de Bacalar estaba integrada por "sesenta soldados, un comandante, un sargento... unos cien vecinos capaces para las armas, veinte indios flecheros y treinta o cuarenta negros libres en igual disposición", pero no cuenta a las mujeres, a los niños y a los ancianos que juntos todos alcanzarían unas 700 personas en 1776. Ya en 1765, James Cook anota que "in number not more than a hundred Spaniards and Indians" en esa villa pobre y con muchos problemas.

${ }^{7}$ La base de esta convivencia se halla en el cultivo de la caña de azúcar que los canarios llevaron a Bacalar y cuya explotación enseñaron a los naturales creando de ese modo una comunidad de práctica con relaciones mutuamente sostenidas y un rápido flujo de información que estimuló la innovación lingüística en tanto que esa actividad significaba un compromiso mutuo entre canarios y nativos y la conciencia de ambos sectores de pertenecer a esa parte del grupo de la población que se dedicaba a esa tarea. 
a causa de los ataques de piratas y corsarios ${ }^{9}$. Sin embargo, el proyecto común de repoblación y las ventajas que ofreció la autoridad, hizo que los indios mayas formaran un grupo de cohesión con los recién llegados a tal grado de que emprendieron juntos incursiones contra los ingleses asentados en el sur de su territorio en las que capturaron cortadores y esclavos negros. Esta actitud de cooperación entre colonos y nativos nos muestra el establecimiento de una red densa de comunicación.

La vida en Bacalar no era fácil pues el lugar era insalubre, muy lejano de los pequeños centros urbanos, con caminos intransitables en la época de lluvias y tierra poco apta para la agricultura. Éstas fueron las razones que los colonos canarios esgrimieron cuando, en 1737 , le pidieron a la autoridad que les continuara pagando el real diario de sustento que les dio durante un tiempo mientras podían cultivar la tierra desde su llegada cuatro años atrás. El gobierno entonces se percató del fracaso inevitable de la colonización del área de Bacalar. En 1744, el gobernador llegó a proponer la demolición del fuerte de San Felipe y de las 15 o 16 casas de las familias no indígenas que habitaban la villa y que éstas fueran trasladadas a Chunhuhub (Bracamonte y Solís, 2006: 452-453).

Por otro lado, la población se vio disminuida a causa de la aparición de la fiebre palúdica en 1770 y de una epidemia de viruela en 1793. Muchos murieron, entre ellos varios canarios que ya habían dejado descendencia y una simiente linguiística que aún perdura. Pese a todo, la población creció y pasó de 2000 personas hacia 1794.

\section{HERENCIA LINGÜÍSTICA}

Estos 149 colonos, destinados por la corona española para repoblar la villa de Bacalar, formaron un grupo peculiar que pronto se acomodó al clima, a la comida y a las faenas propias de la vida del campo, ya que se trataba de familias humildes cuyo transporte había costeado la propia corona española. Con el tiempo, seguramente algunos hombres solteros o casados con mujeres que se quedaron en Canarias tuvieron descendencia con otras mestizas o indígenas, y es de suponerse que ésta conservara formas lingüísticas de padres o de abuelos y que a su vez diera a sus hijos esos mismos elementos de uso en la comunicación cotidiana. Estas formas se pueden observar a nivel léxico solamente, y dar los pormenores de su conservación y uso actual es el objetivo del presente trabajo.

Ahora bien, la convivencia social del grupo originario y el de los colonos estuvo matizada por el uso de formas canarias desconocidas que arraigaron con

\footnotetext{
8 Algunos canarios eran gente de mar (pescadores, calafateros, herreros, carpinteros), otros más tenían otros oficios (barberos, pilotos, comerciantes)
} 
el tiempo, pues debemos entender que para indios, mestizos y mulatos, que comenzaban a aprender el español, el vocablo que oían por primera vez era el que constituía su acervo léxico inicial, viniera de donde viniera como sugiere Lara (2008: 346) que ocurrió en el centro de México. Si a este factor agregamos que la sociedad bacalareña constituía una red social densa (Milroy, 1980) cuyo grado de cohesión e interacción social por relaciones de parentesco, vecindad, ocupación y amistad era marcado, podemos afirmar que era un grupo cada vez más propenso a la conservación de un vernáculo que estaba naciendo de acuerdo con sus normas de uso. Ahí, en ese reducido número de metros cuadrados rodeado de selva y agua se empezó a gestar y a desarrollar la huella linguiística de los canarios que sumaban casi el $50 \%$ de la población total distribuida en 50 casas hacia 1750 (Conover, 2013: 32).

Esta huella está estructurada apenas por algunos adjetivos, verbos y sustantivos. Es una impronta endeble pero valiosa desde el punto de vista linguiístico e histórico, pues hasta ahora no se había registrado el uso actual de estas voces, y aunque no consten en documentos (aunque hay muy pocos que contienen alguna muestra), en ciertos sectores sociales se ha logrado detectar su presencia gracias a la aplicación de un cuestionario estructurado cuyo objetivo fue obtener muestras léxicas canarias usadas por los quintanarroenses ${ }^{10}$. Desde el punto de vista histórico también son dignas de atención, pues son palabras que llegadas a Bacalar en el siglo XVIII en boca de los canarios, echaron raíces y crecieron, un siglo después - exactamente en 1848 y 1858 - viajaron hasta la Honduras Británica ${ }^{11}$, y en 1898 regresaron a territorio mexicano en boca de los fundadores de Payo Obispo (hoy Chetumal) y se quedaron o incluso, continuaron su recorrido hacia Bacalar ${ }^{12}$.

\footnotetext{
${ }^{9}$ Se ha mencionado al pirata Diego Lucifer de los Reyes apodado "El Mulato" que saqueó cada una de las casas y la iglesia en 1642, y del corsario Abraham quien mató a varios vecinos y secuestró a las mujeres de la villa en 1648. Por ello, el cabildo de Bacalar determinó abandonar el territorio e instalarse en Chunhuhub.

${ }^{10}$ El procedimiento para obtener el corpus lingüístico fue el siguiente: después de registrar los generales del informante en una ficha, se le preguntaba si conocía la palabra (abanar, enjillado...), si respondía que sí, se le cuestionaba sobre el significado de la voz, y si la usaba. Al final se le solicitaba un sinónimo con objeto de indagar sobre la posible competencia entre las voces tanto activa como pasivamente.

${ }^{11}$ La gente de Bacalar que huyó en 1858 de los horrores de la Guerra de Castas halló acomodo con sus paisanos que 10 años antes habían llegado a los pueblos norteños de Belice, y empezó entonces un proceso de aclimatación en una sociedad multilingüe en la que se hablaba maya yucateco, español, creole e inglés, pero predominaban los dos primeros pues la población latina era mayor. Fueron más de 20 mil los refugiados yucatecos que se establecieron en Consejo, Corozal y Xaibé principalmente.

12 El recorrido de estas voces de Bacalar hacia las poblaciones asentadas al sur del río Hondo como Corozal, Punta Consejo, Xaibé, San Joaquín, San Román, entre otras, y el regreso a tierras mexicanas en donde han sido documentadas, demuestra que los que llegaron en el siglo XVIII a
} 
Estas nuevas voces llegadas con los canarios a Bacalar proporcionaron a los hablantes mayas, criollos y mestizos la posibilidad de incrementar su léxico pasivo y usarlo en la comunicación cotidiana para hacerlo útil en las diversas actividades de la vida social y en sus propias esferas de acción. Ya en el hogar o en el trabajo, estas palabras nombraron una realidad ya conocida pero de una manera nueva que empezó a ser compartida con los demás usuarios de la familia y de los círculos laborales conformados por redes sociales densas que permitieron situaciones comunicativas informales y familiares intensas. Con los años, ese léxico fue adaptándose hasta convertirse en préstamo establecido cuyo origen sus usuarios mayas, criollos, mestizos y canarios desconocían, seguramente, y logró afianzarse en todas las comunidades de práctica en todos los ámbitos de la sociedad bacalareña del siglo XVIII.

Veamos un ejemplo: Si abanar fue usado en Bacalar con los significados que tenía en Canarias: 'soplar con el abanico', 'avivar la lumbre con el abanador', 'espantar las moscas con la mano o con cualquier objeto', 'agitar la mano o un pañuelo para saludar o llamar a alguien', este uso social fue amplio pues, seguramente, rebasó las fronteras del hogar y se insertó en un tejido más abarcador; es decir, presentó una incrustación en ámbitos ajenos a la vida familiar como el que recoge Santamaría (1984) en Tabasco (no en Bacalar) y que pertenece al campo semántico de la ganadería. s. v. abanar.

La frecuencia de uso de estas nuevas voces puede ser que no se haya visto constreñida por la presencia de hablantes no canarios, pues es de suponer que el número de éstos fuera exiguo en Bacalar. Por otro lado, los que hablaban otra modalidad del español vieron enriquecido su lexicón, y en ellos la competencia entre las palabras ya adquiridas y las nuevas se hizo notoria, puesto que en su comunicación cotidiana apareció un polimorfismo léxico que se fue adaptando a la costumbre lingüística en proceso de creación.

De ese modo, es de esperarse que se haya establecido una competencia entre abanar y abanicar, enchumbado y empapado, rebumbio y desorden, bullicio, alboroto, esgarrada y gargajo, novelero y fisgón, enjillado y enfermo junto a la voz maya t'onán, chicolear y agitar, enjilar y enhebrar o ensartar, lasqueado y desportillado, nené y nene, bebé o niño, papagayo y papalote en los diversos sectores de la población.

En la sección de los no hispanohablantes, se dio, con seguridad, una situación de diglosia en la que la lengua española fue usada en la comunicación más

repoblar la villa de Bacalar sí eran canarios aunque Conover no lo asegure, pues no existe otra explicación sobre el origen de la presencia de estas voces en mi vocabulario, ya que me fueron dadas por mi madre — bilingüe español-creole en su infancia y adolescencia- nacida en 1927 en San Román, Belice, de madre beliceña — hablante de maya, español y creole—, padre mexicano -monolingüe de español- De su presencia en mi léxico infantil y adulto nace la inquietud por conocer más el origen y periplo de estas voces. 
formal, y se relegó el maya y otras lenguas para situaciones familiares. Las voces canarias, sin duda, tuvieron presencia en estilos más formales junto con otras llevadas por esos mismos o por otros colonos, y adquirieron, con el tiempo, una difusión mayor: chubasco, serrote, bagazo, trapiche; pero también en la informalidad aparecieron estos mismos más las otras que son nuestro objeto de estudio. Todas éstas se enclavaron casi exclusivamente en el terreno informal donde su uso fue mayoritario en el gran sector popular - ya que los comerciantes o funcionarios canarios prefirieron radicar en ciudades como Mérida y Campeche-, y cuando empezaron a marcarse con más claridad las diferencias entre las formas culta y la popular, este mismo enclave las puso a salvo de la modalidad impuesta por los hablantes más cultos.

En el sur de Quintana Roo, estas voces estudiadas presentan una fuerte estabilidad semántica semejante a la que conservan en Canarias al designar acciones (abanar, chicolear, enjilar, enjillar, enchumbar, lasquear, novelear, esgarrar), estados (enjillado, gandido, enchumbado, nené, novelero, provocado) y objetos (abanador, bufeo, bulto, caño, esgarrada, flus, hilera, papagayo) muy concretos, y no sufrieron desplazamiento alguno en su significación al ser adoptados por los nuevos usuarios bacalareños, salvo enjillado que no se aplica a las personas flacas o a las frutas mal logradas sino al animal decaído y enfermo.

En el terreno morfosintáctico, solamente el valor adverbial de la forma portuguesa mal 'apenas' (documentada en el sur Quintana Roo) ha sufrido cambios, pues el hablante popular, quien desconoce su significado en portugués, ha creado mal apenas de un modo anómalo, pero que para él significa solamente 'apenas' o 'inmediatamente': "Mal apenas acabe de lavar voy a verte" Esta forma la registra Torres (1981: 107) en la isla de Lanzarote, a la que agrega malamente con el mismo significado e igualmente intensificado: "beseh manese'l día t'on garugao que malamente be lah casah", forma que no he registrado.

\section{LOS MATERIALES}

Abanar. El Diccionario básico de canarismos $(D B C)$ asienta las siguientes acepciones: 'hacer aire, generalmente con el abanador, hacer señas ostensiblemente desde lejos agitando la mano o un pañuelo, para saludar o llamar a alguien, espantar insectos, como las moscas, con la mano o con cualquier otra cosa. En un extenso artículo, el Tesoro Lexicográfico del Español de Canarias (TLEC) asienta que abanar es un portuguesismo que significa 'soplar con el abanico' y 'avivar el fuego con el abanador', que es de uso anticuado en Castilla y llegado al archipiélago directamente del portugués y no a través del habla de colonizadores andaluces y castellanos, que ha sido documentada también en bastantes pueblos de Huelva y de una localidad de Cádiz según el 
ALEA (mapas 725 y 726) y que domina sobre las formas soplillo o soplar según el ALEICan (mapa 575). Abanar también significa 'ahuyentar las moscas con algún objeto que se asemeje al abanico' y 'hacer con la mano señales de llamamiento'. El complejo valor semántico que tiene en las islas se empareja mucho mejor con las acepciones galaico-portuguesas que con la española abanicar.

El DRAE lo registra como 'hacer aire con el abano, y 'avivar la lumbre con el soplillo' solamente usual esta acepción en Canarias y Andalucía, pero nunca en América, en tanto que el Diccionario de americanismos (DA) dice que es 'avivar alguien el fuego mediante un abanico generalmente improvisado' en República Dominicana, Venezuela y Uruguay, lugares en los que hubo notorias migraciones canarias.

En el sur de Quintana Roo, abanar significa 'hacer aire con cualquier objeto' que puede ser un trozo de cartón o plástico, incluso con un abanico, y la acción a veces es asociada a la idea de avivar el fuego "abanar el fuego" o "abanar la lumbre" o bien de 'echarse aire, abanarse', pero nunca a la de espantar moscas "abanar las moscas" u otro insecto o de saludar haciendo señas con las manos, un pañuelo o algo semejante como se registra en Canarias (Millares y Millares, 1932) s.v. abanar. Abanar es una palabra introducida en 1616 (Corbella, 1994-1995: 242-243) en el archipiélago canario, y se documenta con mayor o menor extensión en Andalucía occidental según García Mouton (1991: 249) quien también la registra en la Isla de El Hierro que, desde antiguo, ha sido tierra de emigrantes pues muchos hombres marchaban a Tenerife y de ahí saltaban a Venezuela, México, Cuba, Puerto Rico. Torres (2004: 204) asegura que tanto abanar como abanador llegaron a Lanzarote por vía andaluza.

Corbella, en el artículo citado, menciona que abanar es hoy usual en Andalucía y en zonas de Hispanoamérica como México y Paraguay, aunque no menciona sus fuentes. Me atrevo a pensar que lo que consultó fue el Diccionario de mejicanismos (Dmej) de Francisco Santamaría en el que, en efecto, está registrada la palabra con el significado de 'golpearse la cola las bestias su propio cuerpo, para espantarse y ahuyentar los zancudos y otros insectos que los hostigan' y 'hacer aire con cualquier objeto, usado a guisa de abano'.

No podemos saber con exactitud si abanar sustituyó alguna vez a abanicar en el idiolecto de algún bacalareño indígena o mestizo o mulato o si sucedió lo contrario en el de algún hijo o nieto de canario, lo que sí podemos asegurar es que ambas voces entablaron una singular competencia en la que abanar perdió vitalidad ya que actualmente es poco usada y sólo la he podido documentar en Chetumal, Xcalak y Corozal (en Belice).

Se trata pues, de un portuguesismo llegado a México vía Canarias con escaso uso — como ya se apuntó- pero conocido por todos los sectores sociales de Chetumal. 
Abanador. El TLEC anota que es el 'instrumento para avivar el fuego del brasero', que viene del portugués abanador 'utensilio em forma de leque, para activar a combustào, agitando o ar $^{\prime 13}$; y que tiene varias formas en el archipiélago: abanador en La Palma, La Gomera, la isla de El Hierro, Tenerife y Gran Canaria, abanaor en Lanzarote, abanadore y abanadol en La Gomera, y abanadó en Gran Canaria y Fuerteventura, aunque también es usado en parte de la Andalucía occidental.

En Quintana Roo, tiene el mismo significado, y se enclava solamente en el sector popular y en la población mayor de cuarenta años, de ahí su escaso uso. La voz, igual que abanar, no figura en ningún lexicón de yucatequismos.

Bufeo. El $D B C$ registra las acepciones 'cetáceo grande, resoplido de los cetáceos, ruido de un bufadero'.

En Quintana Roo y Campeche ${ }^{14}$, 'tipo de delfín de piel oscura y rasposa' (Tursiops truncatus). El Dmej asienta que es el nombre que se la da a la tonina y otros cetáceos, aunque no dice en qué parte de México. Así le llaman también en Perú, Bolivia y Colombia a esa especie de delfín según el $D A$, pero no registra su uso en México.

El TLEC dice que bufeo es la forma más corriente de uso documentada ya en los siglos XVI y XVII, a la que se suman bufero y búfalo. Por la descripción proporcionada, se trata del mismo animal mamífero que no ataca a las embarcaciones y conocido con el mismo nombre en Perú, México y Honduras. Ni el $D E M$ ni el $D M$ documentan esta voz, y el DRAE lo incluye como sinónimo de delfín.

Bulto. El DRAE asienta que es 'bolso empleado por los niños para llevar los útiles escolares', en Costa Rica y Venezuela solamente. Sin embargo, en Quintana Roo, el significado es más amplio pues se refiere no sólo al cartapacio sino a 'cualquier bolsa de mano de mujer, monedero, mochila, maletín o portafolios', es decir, es cualquier tipo de bolsa en la que se transporta dinero $\mathrm{y} / \mathrm{o}$ documentos u otros enseres menores.

Esta palabra tiene un gran uso en todos los estratos sociales de la población no solamente del sur quintanarroense ${ }^{15}$, sino en toda la geografía peninsular yucateca, y aparece en el Diccionario del español yucateco (DEY) con un significado muy parecido al que se ha documentado en Quintana Roo.

\footnotetext{
${ }^{13}$ Las definiciones en portugués proceden de Figueiredo (1949), salvo que se indique otra fuente.

${ }^{14} \mathrm{La}$ documentación en este sitio puede verse, amén de la nuestra, en el $D M e j$, s. v. bufeo.

15 "A una vecina de mi mamá la asaltaron ayer y le arrebataron su bulto unos tipos de una moto". Conversación informal con un hablante chetumaleño, varón, de 30 años y de escolaridad baja (primaria terminada) ocurrida el 1 de marzo de 2015.
} 
Caño. El TLEC dice que en Canarias se utiliza para designar a las gárgolas en forma de tubo por las que se desaguan las azoteas y tejados, en tanto que el $D B C$ asienta 'acequia formada por un caballón, que conduce las aguas que discurren por una ladera o por un camino hacia una gavia o un aljibe'. En Quintana Roo, es un canal semicircular de lámina de acero puesto en el borde de la techumbre llamada agua o alero que recoge el agua de lluvia y la conduce hacia un depósito. El DRAE registra 'tubo por donde sale un chorro de agua u otro líquido, principalmente el de una fuente'. Actualmente, es difícil ver en las ciudades quintanarroenses los caños, pues son propios de las construcciones de madera principalmente en Chetumal y la zona sur, y servían para conducir el agua de lluvia hacia unos depósitos de madera llamados curvatos. La voz es conocida por todos los sectores sociales de la población con el significado propio de la región.

Chicolear. El TLEC asienta tres formas: chocaliar, chocoliar y chocallar con el mismo significado y deriva la voz del portugués chocalhar 'vascolhar, agitar, produciendo som semelhante a do chocalho' ${ }^{16}$, 'agitar dentro de um vaso a do una caixa', de amplio uso, pero la forma más general es chocaliar. El DM y el $D A$ registran 'hacer una persona gestos de cariño a otra, lo mismo que el Dmej (s. v. chicolear). EL DECAN y el DHECan registran, además, la forma chocalear con el mismo significado y origen pronunciada chicoliar y cuya documentación, en portugués, la sitúan en el siglo XIII.

Chicolear significa en Yucatán y en casi toda la península yucateca 'agitar un líquido dentro del envase que lo contiene, mediante el sacudimiento de la vasija continente' y "es posible que tenga su origen en el término maya chic, chicah 'bazucar' (Amaro, 1999: 273). Puede tratarse, en efecto, de una palabra híbrida maya-español, o bien de un canarismo de origen portugués. Si se trata de la segunda posibilidad, al tener esta palabra el mismo significado que en maya y una fonética muy similar, ya en su cruce con el español, el hablante nativo no la sintió como una forma de corrupción de sus hábitos lingüísticos y la identificó como propia de su etnia y de sus orígenes familiares sin darse cuenta del proceso de adopción y uso. El DRAE registra la voz con el significado 'decir chicoleos'.

En ningún otro país americano se registran las formas comentadas a excepción de México (península de Yucatán) en donde la presencia de la lengua maya pudo haber influido en su arraigo y posterior difusión a partir del siglo XVIII.

Enchumbar. El DBC registra 'ensopar, empapar de agua'. En el sur de Quintana Roo tiene el significado de 'mojar excesivamente algo, empapar, ge-

16 'Cencerro' en portugués. 
neralmente de agua'. La voz es de uso corriente en Cuba, República Dominicana, Puerto Rico y Uruguay y parece procedente del archipiélago (Álvarez, 1981: 304). A estos países el DECAN adiciona Colombia, Venezuela, Argentina y Ecuador como usuarios de la voz. Al igual que abanar, se le considera un lusismo, pero procedente de la provincia portuguesa Tras-os-Montes según Pérez Vidal (1968: 245) provincia que junto con las de Algarve, el Alentejo, Extremadura, las Bieiras y Minho fueron cuna de los primeros portugueses que llegaron a Canarias. Esto mismo considera Morera (1994: 46) cuando dice que procede del portugués enchumbar 'por-se muito pesado por se molhar'.

Según el $D A$ es de uso corriente en Cuba, República Dominicana y Puerto Rico con el significado de 'empapar' y en los dos últimos también como 'empantanarse un terreno o camino'. Asimismo, registra la voz como usual en el sureste de México, pero no figura ni en el $D E M$ ni en el $D M$, aunque sí en el $D E Y$ con el significado 'acumular agua en una parte o sección de la casa o la calle'.

El TLEC dice que se trata de un portuguesismo trasmontano y que significa 'mojar en exceso, saturar de agua' y también 'empantanarse de agua' (como en Yucatán, República Dominicana y Puerto Rico).

Esta palabra es una de las más conocidas no sólo en el sur quintanarroense sino en otros lugares de la península yucateca, pues se ha podido documentar en Campeche, Mérida, Bacalar, Chetumal, Xcalak y también en Corozal (en Belice).

Enjilar. En Quintana Roo, es 'enhebrar, ensartar el hilo en el ojo de la aguja', significado que recoge el TLEC y que emparenta con enhilar 'ensartar los pescados por medio de un junco, que les entra por las agallas y les sale por la boca'. En Quintana Roo como en Canarias se aspira la /h/ en la pronunciación de la voz que el $D R A E$ registra como 'enhebrar'. La palabra no la registra el $D A, D M, D E M$ y $D E Y$ pero sí el Dmej como 'soltar una serie de expresiones, sobre todo malsonantes e injuriosas'. El $D B C$ asienta 'lanzar, arrojar, tirar, comerse o beberse algo de golpe o con rapidez. El mapa 904 del Atlas Lingüístico de México (Lope Blanch 1990-2000) documenta [enxilár] como única forma documentada en Mérida, Valladolid, Tizimín, Ticul, Campeche, Champotón, Mamantel, Ciudad del Carmen, Felipe Carrillo Puerto y Chetumal, por esta razón resulta extraño que el $D E Y$ no la registre.

El DECAN documenta enhilar con aspiración de /h/ con la acepción 'enhebrar' y también con las de 'lanzar' y 'beber y comer con avidez' de uso en Extremadura y Venezuela sólo la primera de ellas.

Enjillar. El DBC documenta 'dicho de una persona, animal, planta o fruto, no alcanzar su crecimiento normal o su grado de sazón', pero no registra 
enjillado que en Quintana Roo, designa al 'ave de corral quieta y que muestra síntomas de enfermedad'. Millares y Millares (1932: 68) dicen que en Gran Canaria 'se aplica este mismo calificativo al individuo encanijado, falto de desarrollo' y que en Puerto Rico y República Dominicana significa 'flaco y alto de hombros' y 'enjuto, endeble' respectivamente (s. v. enjillado). El DA asienta que en Puerto Rico se refiere a la 'persona o animal raquítico, enclenque'. En Cuba, es 'no cuajar bien el grano de maíz u otro' según Pichardo (1836), y está en desuso, sin embargo en Venezuela, tiene este mismo significado (DECAN y $T L C A)$ y tiene gran vitalidad. Es decir, es un adjetivo que se aplica a frutos mal logrados y personas muy delgadas y con aspecto poco saludable. Y es precisamente este aspecto el que en Quintana Roo se le aplica al ave de corral, pero nunca a las personas o a las frutas. Por su parte, Álvarez (1981: 304) comenta que en Puerto Rico es enjillarse o enjillirse.

Enjillado es, al parecer, un lusismo o galleguismo. Se puede comparar con el portugués engelhar-se 'enrugarse, adquirir pregas, dobrar-se', con engelhado 'enrugado, encarquilhado, fañado, encolhido' y con el gallego enxel(o) 'delgado más de lo regular, débil' (Morais cit. por Catalán, 1989). Pérez Vidal (1968: 232) dice que enjillar 'enflaquecerse' viene del portugués engelhar 'contrahir, murchar' pues el cambio de $e$ ante palatal en $i$ relajada es corriente en portugués y gallego.

El TLEC asienta enjillado como un provincialismo canario con el significado 'enclenque, enteco, enfermizo, esmirriado, desmedrado' aplicado a la persona y documentada en Gran Canaria, y la considera un portuguesismo que viene de engelhado 'que tem gelhas, enrugado, murcho'. Las formas que recoge son varias: esnillado en La Palma, enjellao en La Gomera, enjellado en la isla de El Hierro. Además, registra enjillamiento 'raquitismo' como americanismo.

A pesar de tales competidores, la palabra ha podido sobrevivir y llegado al siglo XXI pues ha sido documentada en Chetumal, Bacalar y Corozal (en Belice). No aparece documentada ni en el $D M, D E M$ y $D R A E$.

Esgarrada. En Quintana Roo, significa 'materia más o menos viscosa y purulenta que se expulsa por la boca'. En la forma escarradura se documenta en Fuerteventura (Morera, 1993: 241) este portuguesismo, y en la de esgarro (del port. esgarro: 'matéria, mais ou menos viscosa e purulenta, que se expele da boca, depois dos esforços da expexctoraçao') en el español atlántico (Morera, 1994: 70).

Pérez Vidal (1991: 126) dice que en La Palma la forma es esgarro, en asturiano occidental es esgarro y esgarrio, en Venezuela esgarre y en Extremadura esjarro. El DA recoge las formas esgarro, esgarre y desgarro con el significado de 'flema' en Puerto Rico.

El TLEC registra escarrar 'expulsar la flema' y escarro 'esgarro, gargajo' 
con las variantes escarriar y ejcarrar en La Palma, ejcarro en Lanzarote y ehjaro en Tenerife.

El $D B C$ documenta esgarro, escarradura y escarrar con los significados de 'flema que se expele de la garganta', 'acción y efecto de escarrar o gargajo, flema que se expele de la garganta' y 'expeler flema' respectivamente, pero no así la forma esgarrada que hemos documentado en el sur de Quintana Roo. El $D R A E$ sólo registra la forma esgarrar 'hacer esfuerzo para arrancar la flema', pero no esgarrada que sí consigna el Dmej como la 'acción de esgarrar' y esgarro como 'esputo que se produce al esgarrar', pero confunde la acción con el producto de ésta al que llama también esgarrar (s. v. esgarrar).

Para los quintanarroenses no hay duda: esgarrar es la acción de arrancar la flema y ésta es la esgarrada. Ambas voces tienen muy poco uso y sólo suele oírse en el sector popular y en personas mayores de 30 años.

Fogaje. El $D B C$ registra 'fuego, erupción de la piel' y 'calor sofocante'. En Quintana Roo y en el resto de la península yucateca, es una 'úlcera o erupción pequeña que sale en el interior de la boca o en los labios debido al calor excesivo en el cuerpo' y es la misma definición que aparece en el Dmej y en el $D E Y$. El $D M e j$ asienta la voz como 'erupción' documentada en Veracruz. El TLEC dice que es 'erupción de la piel' y que proviene del portugués fogagem 'calor de sangue que se manifiesta por erupçào de pele' aunque en América, la acepción más conocida es 'bochorno, calor'.

En Canarias, dice el DRAE es 'fuego, encendimiento de sangre', pero en Colombia, Cuba, El Salvador, Panamá, Puerto Rico y Venezuela es 'calor, bochorno'.

De lo expuesto en el TLCA, vemos que sólo en el noroeste de Argentina el significado de la voz es idéntico al recogido en Quintana Roo.

Gandido. El $D B C$ asienta la forma gandío con el significado 'comilón, glotón' documentada en la isla de El Hierro. El TLEC registra la misma forma y el mismo significado, aclara que es una deformación de gandido, forma ésta registrada en Colombia, Cuba Costa Rica, Venezuela y México. El DMej lo registra en Yucatán y Chiapas con los significados 'glotón, tragón'.

En Quintana Roo, es un adjetivo de muy escaso uso en todos los sectores sociales y se refiere a la 'persona avorazada en el consumo de comida y cuya pretensión es no compartirla con los demás'. El DRAE asienta que es 'comilón, hambrón' en Colombia, Cuba y República Dominicana, pero no registra su uso en Canarias.

Hilera. Es el hilo para coser o costurar en Quintana Roo y norte de Belice. Esta forma más jilera las recoge el TLEC en Tenerife. Lope Blanch (1990: 112) 
registra hilera en Yucatán, Campeche con una amplia penetración en Tabasco que llega hasta Juchitán, Oaxaca.

Cuando la hilera se inserta en el ojo de la aguja se dice enjilar en Quintana Roo y en casi toda la península yucateca. Ahora bien, el $D E Y$ dice que en Yucatán, se le llama hilera sólo al hilo de color blanco pues a los de otros colores se les denomina hilo, y que también es hilera el hilo con que se tejen las hamacas. El DM recoge hilera como 'hilo de coser' en tanto que el DEM no registra dato alguno.

Lasquear. En Quintana Roo, significa 'desportillar' igual que en Canarias pues el TLEC dice que es 'hacer lascas, astillar'. El $D E Y$ (s. v. lasgar) que aclara que es corrupción de lascar. No la registran el $D M, D E M$ y $D R A E$. El $D B C$ registra 'sacar lascas de una cosa' en tanto que el Dmej dice que es 'descascarar, dícese principalmente de los objetos de peltre'.

Nené. En Quintana Roo, es el niño recién nacido o de muy corta edad. El uso de esta voz en Yucatán es tan extendido como en la geografía quintanarroense. Nene —asienta Suárez (1996: 64) — "es voz llana que en Yucatán se usa como aguda con la $e$ final glotalizada... empleando la voz para ambos géneros: el nené y la nené", que refleja un posible influjo de la lengua maya tan inclinada a las articulaciones glotales agudas (Lope Blanch,1990: 88).

Pienso que tanto la influencia maya como la canaria han obrado sobre la voz para hacerla más usual que bebé o nene en Yucatán, Quintana Roo, en México, en el norte de Belice, y también en Campeche en donde, además, se usan las formas tierno y bebé. Y en la forma canaria esta influencia es evidente en "la acentuación oxítona (que) debe provenir del portugués, donde nené es equivalente a bebé, criatura, niño recién nacido" (TLCA: s. v. nené).

Novelero. El $D B C$ registra 'muy aficionado a las fiestas'. En Canarias, una persona novelera es la que anda de un lado a otro noveleando. En Quintana Roo, el significado es muy próximo al que registra el $D R A E$ pues se refiere a la persona entrometida y fisgona que anda investigando cualquier asunto $\mathrm{y}$, a veces, esculcando en diversos sitios. Es voz poco usual que sólo puede oírse en la población mayor de cuarenta años y exclusivamente en el sector popular. El Dmej asienta que en Cuba y Tabasco es 'persona aprehensiva, aspaventera y aparatosa'. El $D A$ dice que se refiere a "la persona inquieta, curiosa, dispuesta a participar en cualquier actividad" de uso en Guatemala, Honduras, Cuba, Puerto Rico y República Dominicana.

Novelero es una persona fisgona más que entrometida, en tanto que novelear es una actividad más visual que oral o corporal, acciones estas dos últimas que convierten al individuo propiamente en un entrometido. Ser novele- 
ro es buscar algo con la mirada en un baúl o una caja, sobre una mesa o en un conjunto de cosas diversas en cualquier sitio, a veces ayudado con las manos. La voz la pude documentar en Chetumal y Xcalak, y su presencia en Quintana Roo se debe, con seguridad, a los colonos canarios.

Hay que anotar que el $D B C$ documenta novelerear como la acción de 'andar de fiesta en fiesta'. Esta misma forma la registra Álvarez (1981: 306) en Puerto Rico, además de novelero. En Quintana Roo, la forma es novelear y tiene el significado de 'fisgonear en casas ajenas en busca de algo novedoso o sorpresivo'.

Papagayo. En Quintana Roo y en el resto de la península yucateca — salvo en una parte de un amplio sector de Cancún, Isla Mujeres, Tulum, Playa del Carmen y Cozumel-, papagayo es le denominación general para referirse a lo que en el resto de México se conoce como papalote o cometa.

El mismo significado de 'cometa' lo documenta el TLEC en Tenerife y agrega que papagaio es la denominación más difundida en Portugal y de idéntico valor en Venezuela. Lope Blanch (1990: 82) señala que papagayo "parece ser la forma más usada en el Caribe; se ha documentado en Cuba, Venezuela e inclusive en la Argentina", sitios en los que hubo importantes migraciones de Canarias. Se trata pues, de un portuguesismo llegado a la península yucateca con los colonos canarios que compitió, seguramente, con el nahuatlismo papalote (incluso en los barrios nahuas de Mérida) ${ }^{17}$ y logró imponerse sobre él.

Provocado. El TLEC registra 'náuseas, malestar que se tiene antes de devolver' documentado en Tenerife, Lanzarote, La Gomera y Fuerteventura, en tanto que el DRAE no registra la voz pero sí dice que provocar es 'vomitar lo contenido en el estómago'. En Quintana Roo, es un adjetivo referido a la persona que siente deseos de vomitar, significado que es el mismo que en Canarias y cuyo uso es generalizado no únicamente en el sur de Quintana Roo sino en toda la península de Yucatán y norte de Belice. El $D B C$ no registra la voz pero sí provocar 'dar o sentir ganas de vomitar' y provocativo 'que por su actitud inconveniente produce una sensación cercana a la náusea'. El significado que tiene en Canarias y en la península yucateca no aparece en ninguno de los otros lexicones consultados, aunque el DECAN asegura que se usa en Luisiana.

Rebumbio. El DBC y Millares y Millares (1932) registran 'confusión, desorden, abundante concentración de personas o de cosas aglomeradas en un lugar', en tanto que González (1999: 493) dice que es una 'confusión, desorden,

17 Para otros aspectos sobre los habitantes "mexicanos" de los barrios urbanos de Mérida puede verse el estudio de Pedro Bracamonte y Sosa (2005). 
mezcla de gentes o de cosas de varias clases'. En Quintana Roo, significa 'relajo, desorden producido por algún acontecimiento'.

El TLEC recoge rebumbio como 'alboroto, escándalo, bulla, barullo, desorden, manifestación de protesta o alegría'. Se trata de significados múltiples en que los semas de confusión y desorden prevalecen en las acciones de las personas, de ahí que, en Quintana Roo, se diga que un rebumbio es producido por algún acontecimiento que afecta a un grupo social, y no como asienta el Dmej 'revoltijo de materias líquidas' o ‘desordenar cosas puestas en orden' propio del habla tabasqueña.

El DRAE sólo registra 'ruido retumbante', significado que resulta menos amplio que el que tiene en Canarias y América.

\section{CONCLUSIONES}

El implante de los elementos léxicos llegados a Bacalar desde Canarias debió de darse en una población pequeña conformada por las familias de los miembros del cabildo y de la guarnición, algunos mestizos y españoles solteros, escasos mulatos e indígenas que eran mayoría. Si atendemos a lo que Gerhard (1991: 59-60) ${ }^{18}$ nos dice sobre la población bacalareña, podemos inferir que ésta no llegaba a los 300 individuos en 1733. Es decir, que los 149 colonos arribados entre ese año y 1735 constituyeron casi el 50\% del total, porcentaje importante para lograr que el arraigo léxico resultara perenne en ese barrio que era el pueblo mismo.

Se trata de verbos, sustantivos y adjetivos que se incrustaron en ciertos bloques de la vida material de la sociedad bacalareña. Así tenemos que para nombrar los enseres de uso doméstico o alguna de sus características, los bacalareños usaron hilera, abanador, bulto, lasqueado, chicoleado, enchumbado, enjilado; para aludir a los aspectos de higiene, salud o enfermedad utilizaron fogaje, provocado, enjillado (sólo para las aves); para recriminar conductas ajenas o propias prefirieron gandido; para referirse al estado de los asuntos sociales echaron mano de rebumbio; para aludir a obras hidráulicas usaron caño; para el delfín eligie-

${ }^{18}$ De un documento casi ilegible, Gerhard obtiene datos que aseguran que Bacalar, en 1688, tenía una población menor a 120 personas. Refiere, además, que en 1727 el gobernador envió un destacamento a la villa y que dos años más tarde fueron 40 soldados los que engrosaron la guarnición y se dedicaron a la construcción del fuerte de San Felipe y de las 7 casas para recibir a los colonos canarios. En 1733, los únicos pobladores eran las familias de estos soldados, las de los miembros del cabildo reinstalado, algunos vecinos solteros (mestizos, indios y mulatos). Años después (exactamente 33) de la llegada de los primeros colonos, Bacalar tenía 62 soldados, 100 residentes españoles y entre 30 y 40 negros libres (no menciona mujeres, niños ni descendientes de los canarios). 
ron bufeo, y para la convivencia familiar fueron grandes usuarios de nené, abanar, papagayo, enchumbar, enjilar chicolear.

Varias de estas voces son de origen portugués que llegaron a las Canarias por la vía andaluza o castellana o directamente de hablantes portugueses ( $a b a$ nar, enjillado, fogaje, papagayo, enchumbar) o son derivadas de otras con ese origen (esgarrada, chicolear). Otras son castellanismos ya obsoletos en Castilla y sólo usados en Canarias y en América (gandido, novelero, nené) o son creaciones canarias compartidas solamente con el sureste de México (provocado, hilera, chicolear, rebumbio, enjilar, lasquear) o con otros países de América (bufeo).

En cuanto a su distribución diatópica, y después de analizar varios documentos, podemos ver que estas voces tienen vitalidad en 19 países americanos hispanohablantes más Belice, y que en México, su uso es mayor en la península de Yucatán que en Tabasco, Chiapas, Oaxaca y Tamaulipas donde también se han documentado.

La vitalidad que tienen estas voces en la península yucateca es semejante a la que se ha documentado en Belice, Cuba, Venezuela, República Dominicana y Colombia, pues varias de ellas son compartidas entre estos sitios. Como es lógico, la cercanía de Bacalar con Belice, los tratos comerciales marcados que hubo entre los ingleses y los mexicanos y canarios de la zona, y el asentamiento de miles de yucatecos en el sur del río Hondo durante la Guerra de Castas (1847-1902) que produjo la fundación de Corozal, Consejo, San Román, Xaibé y otros pueblos en la Honduras Británica, hace que el número de estas voces compartidas entre quintanarroenses y beliceños sea mayor que con los habitantes de los otros sitios americanos. Es decir, parte del léxico patrimonial de los hispanohablantes beliceños tiene su origen en esta impronta canaria asentada en Bacalar en la tercera década del siglo XVIII.

Y eso no es todo. Este acervo léxico llevado por los yucatecos y descendientes de canarios a Belice, retornó a México al fundarse, en 1898, el pueblo fronterizo de Payo Obispo (hoy Chetumal) con parte de esos mismos pobladores que atravesaron el río Hondo hacia el sur 40 años antes y con sus herederos quienes lo mantuvieron y transmitieron a sus hijos y nietos.

En 1904 a sólo 6 años de la fundación de Payo Obispo, la población estaba conformada por 45 mexicanos casi todos de origen yucateco, 11 hondureños, 3 jamaiquinos, 1 cubano, 2 estadounidenses y 186 beliceños de los cuales 148 eran descendientes de yucatecos y hablaban español yucateco, y sólo 38 inglés (Vallarta, 2001: Anexo 2). Por la conformación social de este pueblo fronterizo nos podemos dar cuenta de que el dialecto usado en la comunicación cotidiana era el español yucateco con todo el fárrago de la herencia canaria arraigada desde hacía más de 100 años, herencia que, como se ha dicho, llevaron los bacalareños a la Honduras Británica en 1848 y 1858 y que retornó a tierras mexicanas en 1898 cuando se fundó esta población en la bocana del río Hondo. 
Hoy, estas voces siguen en plena efervescencia (no todas), y en los registros del habla popular es donde mayormente pueden oírse en el sur de Quintana Roo, en toda la península yucateca (algunas) y en los distritos norteños de Belice aludiendo a la compleja realidad de los grupos humanos heterogéneos que conforman las diversas sociedades regionales americanas en donde se habla español.

\section{BIBLIOGRAFÍA}

ALEA = Alvar, Manuel, Antonio Llorente y Gregorio Salvador (1961-1973): Atlas Lingüístico y Etnográfico de Andalucía, Granada, Univ. de Granada/CSIC.

ALEICan = Alvar, Manuel (1975, 1976, 1978): Atlas Lingüístico y Etnográfico de las Islas Canarias, Las Palmas de Gran Canaria, Cabildo Insular de Gran Canaria.

Álvarez Nazario, Manuel (1981): "Relaciones histórico-dialectales entre Puerto Rico y Canarias", en, I Simposio Internacional de la Lengua Española, Las Palmas de Gran Canaria, Cabildo Insular de Gran Canaria, pp. 289-310.

Amaro, Jesús (1999): Vocabulario de el nayeísmo en la cultura de Yucatán, México, Universidad Autónoma de Yucatán.

Antovich, M. y Alonzo, R. (2010): Hechos de Yucatán, México, Secretaría de Educación del Gobierno del Estado de Yucatán.

Bracamonte y Sosa, Pedro (2005) "Los solares urbanos de Mérida y la población territorial indígena en el Yucatán colonial”, en Pablo Yanes, Virginia Molina y Óscar González (coords.), Urbi indiano. La marcha a la ciudad diversa, México, Univ. Nacional Autónoma de México, pp. 231-265

Bracamonte, Pedro y Gabriela Solís (2006): "Insumos e idólatras. Los mayas del Caribe peninsular durante la colonia", en El Caribe mexicano. Origen y conformación, siglos XVI y XVII, México, Miguel Ángel Porrúa/Universidad de Quintana Roo, pp. 425-522.

Calderón, José A. (1953): Historia de las fortificaciones en la Nueva España, Sevilla, Escuela de estudios Hispano-Americanos.

Catalán, Diego (1989): El español. Orígenes de su diversidad, Madrid, Paraninfo.

Conover, Carlos (2013): Llave y custodia de esta provincia. El presidio de San Felipe Bacalar ante los asentamientos británicos de la península de Yucatán (1779-1798), tesis de maestría (inédita), México, Univ. Nacional Autónoma de México.

Cook, James (1765) Remarks on passage from the River Balise in the bay of Honduras to Merida; capital of the province of Jucatan in the Spanish West Indies, London, Printed for C. Parker.

Corbella, Dolores (1994-1995): "Estudio de los portuguesismos en el español de Canarias: cuestiones pendientes", Revista de Filología Románica, 11/12, pp. 237-249.

DBC = Academia Canaria de la Lengua (2010): Diccionario básico de canarismos, Las Palmas de Gran Canaria, Academia Canaria de la Lengua.

$D A=$ Asociación de Academias de la Lengua Española (ASALE) (2010): Diccionario de americanismos. Lima, Santillana.

$D M=$ Academia Mexicana de la Lengua (2010): Diccionario de mexicanismos, Concepción Company (dir.), Siglo XII editores, México.

DEM = Luis Fernando Lara (dir.): Diccionario del español de México (2010), México, El Colegio de México.

DMej = Ramos I Duarte, Félix (1896): Diccionario de mejicanismos. Colección de locuciones $i$ frases viciosas, Méjico, Imprenta de Eduardo Dublan. 
Dmej = Santamaría, Francisco (1984): Diccionario de mejicanismos, México, Porrúa.

DRAE = Real Academia Española (2001): Diccionario de la real Academia española, Madrid, Espasa-Calpe.

DEY = Guiémez, Miguel (2011): Diccionario del español yucateco, México, Universidad Autónoma de Yucatán/Plaza y Valdés.

DECAN = Corrales, Cristóbal y Dolores Corbella (2009): Diccionario Ejemplificado de canarismos, La Laguna, Instituto de Estudios Canarios.

DHECan = Corrales, Cristóbal y Dolores Corbella (2013): Diccionario histórico del español de Canarias, La Laguna, Instituto de Estudios Canarios.

Figueiredo, Cándido de (1949): Diccionário da língua portuguesa, Lisboa, Livraria Bertrand.

García Bernal, Manuela (2000): "Las islas Canarias y Yucatán: la importancia de un comercio marginal (1700-1750)", en Historia de Canarias y sus relaciones con América. Economía y comercio, Las Palmas de Gran Canaria, Cabildo de Gran Canaria, pp. 1966-1989.

García Mouton, Pilar (1991): "El léxico de la isla de El Hierro", Revista de Dialectología y Tradiciones Populares, XLVI, pp. 247-264.

Gerhard, Peter (1991): La frontera sureste de la Nueva España, México, Univ. Nacional Autónoma de México.

González, M. ${ }^{a}$ Isabel (1999): Análisis y descripción onomasiológica del léxico canario, Tesis de doctorado (inédita), Universidad de La Laguna.

Lara, Luis Fernando (2008): "Historia de la expansión del español por México", Nueva Revista de Filología Hispánica, LVI, 2, pp. 297-362.

Lope Blanch, Juan (1990): Investigaciones sobre dialectología mexicana, México, Univ. Nacional Autónoma de México.

Lope Blanch, Juan (dir.) (1990-2000): Atlas lingüístico de México, México, El Colegio de México/Universidad Nacional Autónoma de México/Fondo de Cultura Económica.

Millares, Luis y Agustín Millares (1932): Cómo hablan los canarios. Refundición del léxico de la Gran Canaria, Las Palmas de Gran Canaria, Tipografía "Diario de Las Palmas".

Milroy, Lesley (1980): Language and social networks, Oxford, Blackwell.

Morais, António de (1949-1959): Grande Diccionário da língua portuguesa, Lisboa, Confluencia.

Morales Padrón, Francisco (1950): "El desplazamiento a las Indias desde Canarias", El museo canario, 33-36, pp. 1-24.

Morera, Marcial (1993): "Portuguesismos en el habla de Fuerteventura", Tebeto: Anuario del archivo histórico insular de Fuerteventura, 6, pp. 235-254.

Morera, Marcial (1994): "Lusismos en el español atlántico", Anuario de letras, 32, pp. 37-97.

Pérez Vidal, José (1955): "Aportación de Canarias a la población de América. Su influencia en la lengua y en la poesía tradicional", Anuario de estudios atlánticos, 1, pp. 91-197.

Pérez Vidal, José (1968): "Comportamiento fonético de los portuguesismos en Canarias", Revista de Dialectología y Tradiciones Populares, 24(3), pp. 219-252.

Pérez Vidal, José (1991): Los portugueses en canarias. Portuguesismos, Las Palmas Gran Canaria, Cabildo Insular de Gran Canaria.

Pichardo, Esteban (1836): Diccionario provincial de voces cubanas, La Habana, La real marina.

Suárez, Víctor (1996): El español que se habla en Yucatán, México, Universidad Autónoma de Yucatán.

TLEC = Corrales, Cristóbal, Dolores Corbella y M. ${ }^{a}$ Ángeles Álvarez (1992): Tesoro lexicográfico del español de Canarias, Madrid, Real Academia Española / [Santa Cruz de Tenerife], Gobierno de Canarias.

TLCA = Corrales, Cristóbal y Dolores Corbella (2010): Tesoro léxico canario-americano, Las Palmas de Gran Canaria, Cabildo de Gran Canaria/Casa de Colón.

Torres Stinga, Manuel (1981): "Influencia portuguesa en el habla de Lanzarote", Revista de Filología de la Universidad de La Laguna, 0, pp. 103-110. 
Torres Stinga, Manuel (2004): "Situación del español de Lanzarote. Estado actual y perspectivas de futuro" en X Jornadas de Estudios sobre Lanzarote y Fuerteventura, Arrecife, Cabildo Insular de Lanzarote y Cabildo Insular de Fuerteventura, pp. 187-221.

Vallarta, Luz (2001) Los payobispenses. Identidad, población y cultura en la frontera MéxicoBelice, México, Universidad de Quintana Roo.

Fecha de recepción: 24 de septiembre de 2014

Fecha de aceptación: 6 de abril de 2015 